\title{
Examining spatial concordance of genetic and species diversity patterns to evaluate the role of dispersal limitation in structuring headwater metacommunities
}

Debra S. Finn

N. Leroy Poff

Follow this and additional works at: https://bearworks.missouristate.edu/articles-cnas

\section{Recommended Citation}

Finn, Debra S., and N. LeRoy Poff. "Examining spatial concordance of genetic and species diversity patterns to evaluate the role of dispersal limitation in structuring headwater metacommunities." Journal of the North American Benthological Society 30, no. 1 (2011): 273-283.

This article or document was made available through BearWorks, the institutional repository of Missouri State University. The work contained in it may be protected by copyright and require permission of the copyright holder for reuse or redistribution.

For more information, please contact BearWorks@library.missouristate.edu. 


\title{
Examining spatial concordance of genetic and species diversity patterns to evaluate the role of dispersal limitation in structuring headwater metacommunities
}

\author{
Debra S. Finn ${ }^{1}$ AND N. LeRoy Poff ${ }^{2}$ \\ Department of Biology and Graduate Degree Program in Ecology, Colorado State University, \\ Fort Collins, Colorado 80523 USA
}

\begin{abstract}
Given the unique spatial structure of stream habitat and the stochasticity characteristic of lotic ecosystems, metacommunity approaches hold much promise in the field of stream ecology. We take advantage of the tight parallels between neutral theories of molecular evolution and community assembly and present a novel conceptual approach to evaluating the role of stochasticity and dispersal limitation in structuring stream metacommunities. The analogous neutral frameworks generate similar expectations for the spatial structure of species comprising communities and genes comprising populations, particularly among patchily distributed, isolated local habitats (e.g., headwater streams) where among-stream dispersal is expected to be limited. Our emphasis is on the conceptual value of this approach, but we also used a limited data set composed of intensively sampled community and population-genetic data collected from 5 to 7 Rocky Mountain alpine streams for illustrative purposes. We characterized neutral population genetic structure as mitochondrial haplotype distributions for the blackfly Prosimulium neomacropyga, which shows strong genetic isolation by distance across the study region. We assessed community structure as the relative frequencies of ecologically similar species in the family Chironomidae collected annually over 2000-2003. Species richness was positively correlated with haplotype richness across streams $(r=0.55)$, and analogous methods revealed significant $\beta$ diversity at both the population-genetic $\left(F_{S T}=0.23\right)$ and the community $\left(F_{S T}=0.16\right)$ levels. However, a more spatially explicit comparison of pairwise community dissimilarity and genetic distance revealed no evidence of correlation (Mantel test, $r=-0.18, p=0.54)$, a result suggesting no effect of spatial distance on community similarity at the relatively fine spatial scale of our study. We discuss 2 key arguments to explain the lack of community distance decay: 1) unaccounted environmental differences among streams, and 2) varying spatial and temporal scales of neutral processes (including genetic drift and ecological drift; i.e., stochastic temporal change) between population-genetic and community levels. Evidence for both selective and neutral explanations is compelling in this system. The explanations cannot be disentangled with the current data, but the study has strong heuristic value that we hope will stimulate future efforts in stream metacommunity analysis.
\end{abstract}

Key words: neutral theory, isolation, dispersal, migration, ecological drift, gene flow, population genetics, dendritic network, community ecology.

The metacommunity framework has been applied in the field of stream ecology only recently (Thompson and Townsend 2006, Heino and Mykrä 2008, Brown and Swan 2010), but underlying premises of the concept, particularly the fundamental importance of dispersal in community assembly and diversity patterns, are long-standing themes for stream ecologists (Townsend 1989, Cooper et al. 1990, Palmer et al.

\footnotetext{
${ }^{1}$ Present address: Department of Zoology, Oregon State University, Corvallis, Oregon 97331 USA. E-mail: finnd@ science.oregonstate.edu

${ }^{2}$ E-mail address: poff@lamar.colostate.edu
}

1996). Embedded in the concept of dispersal- or mobility-control (Townsend 1989) on stream community structure is the idea that stochastic, rather than deterministic, processes are of prime importance for stream community assembly (Thorp et al. 2006). Hence, competitive exclusion is rarely an expectation in streams. Instead, habitat dynamism governs coexistence at the reach scale of a multitude of species having similar ecological requirements (Grossman et al. 1982, Poff 1997, Palmer et al. 2000, Heino 2005). When the local community is defined at the reach scale (and metacommunity at the landscape scale), metacommunity concepts are likely to be particularly 
useful in streams (Thompson and Townsend 2006, Heino and Mykrä 2008).

Much groundbreaking work on metacommunity concepts, such as patch dynamics, has been undertaken in streams (Pringle et al. 1988, Townsend 1989), but most of this work considered communities at within-stream spatial scales. Patch dynamics also is expected to operate at the among-stream spatial scale (Thorp et al. 2006, Lytle 2008), and a full range of metacommunity models is now being developed and tested at this broader scale (Thompson and Townsend 2006, Heino and Mykrä 2008, Brown and Swan 2010).

Neutral metacommunity processes might be relevant in streams because neutral theory (Bell 2000, Hubbell 2001) predicts that dispersal limitation by the physical distance among local communities is the dominant process driving spatial patterns of community structure. Studies that have explicitly addressed neutral theory in streams have revealed the importance of space/distance, in combination with local environmental differences, in influencing stream metacommunity structure (Thompson and Townsend 2006, Heino and Mykrä 2008). Distance also emerges as a key influence on spatial diversity patterns in other stream systems (Urban et al. 2006, Mykrä et al. 2007, Sei et al. 2009). These empirical studies and conceptual models (Fagan 2002, Grant et al. 2007) suggest that spatial arrangement of stream segments and variable dispersal among them are likely to be important considerations in stream community assembly. However, the spatial context of community structure often has been ignored in stream community studies (but see Brown and Swan 2010).

In contrast, population-genetics research in streams typically focuses on the role of space and dispersal in generating biological pattern. This avenue of research has resulted in some general models linking genetic diversity patterns, landscape structure, and species' dispersal traits. For example, locations of populations within stream networks probably influence amongstream dispersal rates (Finn et al. 2007, Hughes 2007, Hughes et al. 2009). Specifically, populations occupying isolated headwaters often show strong genetic structure, particularly in mountainous regions (Hughes et al. 1999, Wishart and Hughes 2003, Finn et al. 2006, 2007). This observation suggests that spatial isolation of headwaters allows stochastic processes to dominate population-genetic structuring in species having a limited capacity for among-stream dispersal.

Inference in population genetics is derived from the neutral theory of molecular evolution (Kimura 1968, 1983) and, therefore, hinges on the statistical properties of stochastic processes, such as mutation, genetic drift, and migration (dispersal). Direct parallels can be drawn between neutral theories at the populationgenetic and community levels (Chave and Leigh 2002, Etienne and Olff 2004, $\mathrm{Hu}$ et al. 2006). Alternative forms of a gene (alleles or haplotypes) in a population are analogous to species in a community, genetic mutation is analogous to speciation in creating new forms, random genetic drift in populations is analogous to ecological drift (random fluctuations in species relative abundances; Hubbell 2001) in communities, and metacommunities are analogous to spatially structured populations.

Because of the striking similarity of neutral theories at the community and population-genetic levels, spatial patterns of species and genetic diversity can be hypothesized to be positively correlated across the same set of habitat patches in cases where stochasticity and dispersal limitation are expected to be strong drivers at both community and population-genetic levels. Under both neutral theories, genetically diverse populations are expected to occur in the same locations as species-diverse communities and vice versa (Vellend 2003, Etienne and Olff 2004). The (essentially neutral) theory of island biogeography (MacArthur and Wilson 1967) conceptualizes the key reasoning behind this expected pattern. Habitat size and isolation influence rates of stochastic immigration and extinction of both species and genes. Under neutrality, pairwise patterns of community dissimilarity and intraspecific genetic distance also can be correlated (Moritz 2002), and both are expected to be correlated with effective distance between site pairs. This pattern of increasing dissimilarity with distance is termed distance decay at the community level (Nekola and White 1999) and isolation by distance at the population-genetic level (Wright 1943).

Given the importance of stochasticity and dispersal in stream communities, these types of parallels between community and population genetic structure might be expected to occur, particularly in stream types that are strongly dispersal-limited (Sei et al. 2009). Stream ecologists have begun to evaluate simultaneously co-occurring community and population-genetic patterns (Bonada et al. 2009, Sei et al. 2009), but the direct conceptual and mathematical linkages between the neutral theories at both organizational levels have yet to be explored. We present an approach to link co-occuring metacommunity and population-genetic spatial analyses under neutral theories. We demonstrate this approach with an empirical data set from Rocky Mountain headwater streams that is limited in sample size and geographic extent but consists of intensively sampled species and genetic-diversity data that render it useful for heuristic purposes. 
The benthic communities of Rocky Mountain alpine headwater streams are well-suited for testing the community/population-genetic relationship under neutral theory for several reasons. First, headwater streams in general (Heino et al. 2005, Clarke et al. 2008) and headwater streams occupying mountainous regions in particular (Finn and Poff 2005, Monaghan et al. 2005) often have greater $\beta$ (among-stream) diversity than do higher-order reaches. This pattern is consistent with neutral theory, assuming significant dispersal limitation (Hubbell 2001), and follows logically from the fact that hydrologic connectivity is negligible among headwaters (Fagan 2002, Gomi et al. 2002). Second, flight activity of many alpine-stream insects occurs predominantly within close proximity of the stream (Finn and Poff 2008), a pattern further suggesting limited dispersal across a relatively harsh terrestrial landscape. Third, population genetics studies of 2 alpine-stream insects in the Rocky Mountains have corroborated that among-stream dispersal is rare and strong patterns of isolation by distance occur across short spatial extents (on the order of tens of kilometers; Finn and Adler 2006, Finn et al. 2006).

We present a comparison of population-genetic and community data collected in the same alpine headwater streams, during the same time period, to assess concordance of genetic-and species-diversity patterns under neutral theories at both levels of organization. We evaluated concordance at a spatially implicit level (i.e., geographic locations of sites ignored) by assessing the relationship between local species and genetic diversity across the streams. We also asked whether spatially explicit (i.e., relative locations of sites incorporated) patterns of genetic isolation by distance are correlated with decay of community similarity. We hypothesized that: 1) species and genetic richness are positively correlated among headwater streams, 2) communities have significant spatial structure (i.e., a significant proportion of variance in community structure can be explained at the among-stream level), as previously shown for population genetic patterns of a representative species (Finn et al. 2006), and 3) distance decay is positively correlated with genetic isolation by distance in these streams.

\section{Methods}

\section{Study sites and collections}

Our focal metacommunity occupied a $30-\mathrm{km}^{2}$ area of contiguous alpine zone in northern Rocky Mountain National Park, Colorado. This area was designated previously as the Hagues [Peak] alpine island (Finn et al. 2006). Headwater streams emerging from this high-altitude area flow in all directions from the central origin (Fig. 1A, B), and each stream is itself island-like with respect to its primary inhabitants, insects (Ward 1994). Neighboring streams often occur in different major drainage basins. As such, hydrologic connectivity among streams is extremely low, and among-stream dispersal is expected to occur primarily via terrestrial movement. The regionally common alpine-specialist black fly (Diptera:Simuliidae) Prosimulium neomacropyga shows strong genetic structure across the Hagues alpine island, and significant isolation by distance indicates the importance of dispersal limitation in these streams (Finn et al. 2006). We limited our analyses to the set of alpine streams occupying this limited spatial extent because the previous genetic studies showed the strongest effect of isolation by distance at this scale (Finn and Adler 2006, Finn et al. 2006).

We sampled benthic invertebrates from 5 environmentally similar $1^{\text {st }}$-order streams in the Hagues region, focusing in each stream on reaches 8 to $12 \mathrm{~m}$ in length. We took 3 replicate Surber samples $\left(900 \mathrm{~cm}^{2}\right)$ per stream once each August for $4 \mathrm{y}$ (2000-2003) at 4 of the 5 streams and for 3 y (20012003) at the remaining stream (ELK; Fig. 1A, B). We immediately preserved specimens in $70 \%$ ethanol for transport to the laboratory.

The reaches occupied a narrow altitudinal range of 3355 to $3452 \mathrm{~m}$ asl, and the high altitudes led to very small watershed sizes $\left(<2 \mathrm{~km}^{2}\right)$. Although streams were proximate in plan view, many were bordered by steep drainage divides extending up to 600 vertical $\mathrm{m}$ above stream elevation (Fig. 1A, B). For each reach, we collected samples only in areas of loosely organized rocky substrate and low $(<5 \%)$ local channel slope to minimize environmental heterogeneity among streams. In August 2001, we characterized habitat size for each stream as average wetted perimeter (Gordon et al. 1992) calculated across 5 cross-stream transects, spaced 1.5 to $2 \mathrm{~m}$ apart along each sampling reach. All sites were essentially undisturbed by human activity.

\section{Taxa}

Given the high functional diversity among benthic species in this area (Finn and Poff 2005) and the taxonomic uncertainty for some groups, we limited our community-level analyses to the family Chironomidae. Chironomidae make up a large proportion (typically $>50 \%$ of individuals and biomass) of the total macroinvertebrate assemblage in alpine streams of the study region (Ward 1986, Finn and Poff 2005). Colorado alpine-stream chironomids are predominantly collector/gatherers (sensu Merritt and Cum- 
A
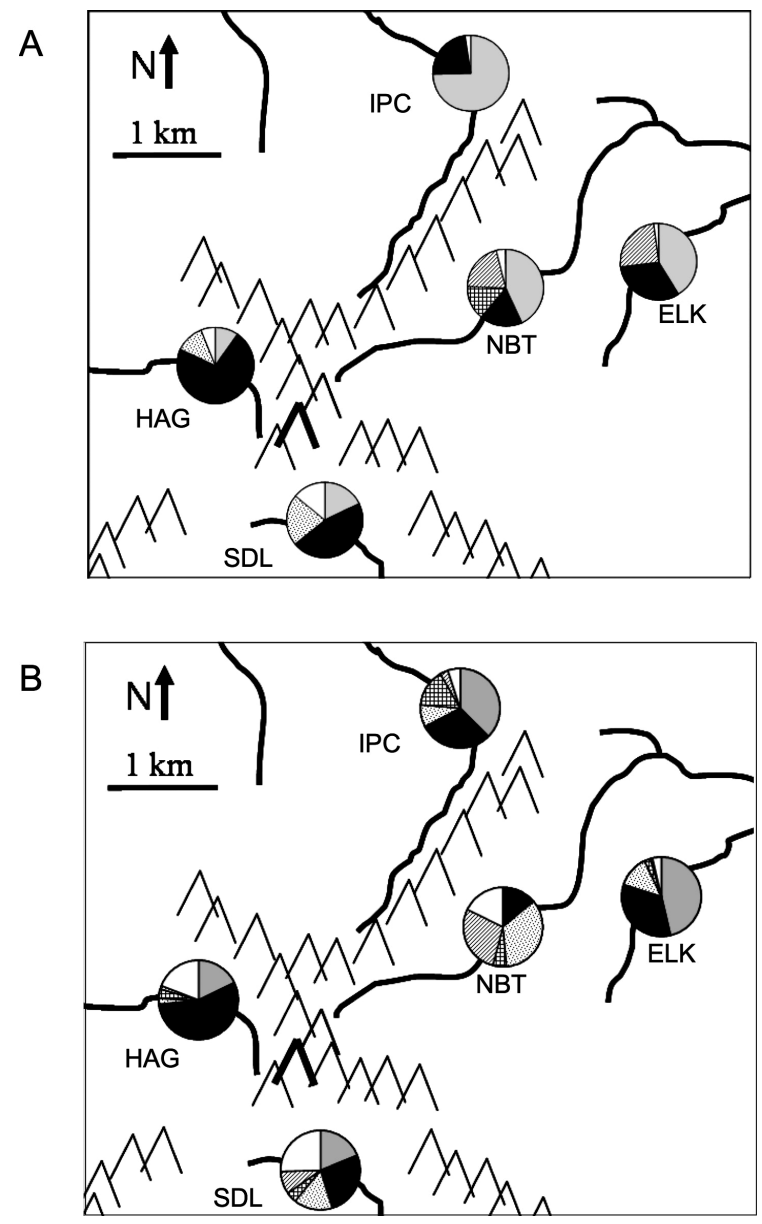

Haplotype 1

Haplotype 2

Haplotype 3

Haplotype 6

Haplotype 14

Less frequent haplotypes

\author{
Diamesa sp. \\ Cricotopus/Orthocladius sp. \\ Eukiefferiella sp. \\ Parorthocladius sp. \\ Tvetenia sp. \\ less frequent spp.
}

FIG. 1. Schematic map of the Hagues Peak alpine island (simplified from Finn et al. 2006). Inverted Vs indicate major ridgelines extending 400 to $600 \mathrm{~m}$ above stream elevation, solid lines indicate alpine headwater streams, and pie charts indicate sampling reaches. A.-Pie charts indicate distribution of common Prosimulium neomacropyga cytochrome c oxidase subunit I (COI) haplotypes (as per Finn et al. 2006), with individual haplotypes representing $<5 \%$ of total genetic diversity shaded white. B.-Pie charts indicate distribution of common Chironomidae species, with all species representing $<5 \%$ of total species abundance shaded white.

mins 1996). Some chironomids can be classified into other trophic categories (e.g., subfamily Tanypodinae are predators), but such specimens were rare in our collections and were excluded from analyses. Therefore, the community of interest was ecologically similar, as per Hubbell (2001), who suggested that generalist feeders might be the most likely type of assemblage in which to expect evidence of stochastic, dispersal-limited assembly. Chironomidae were a taxonomically diverse group at our sites, and all individuals were identified to the species level with the help of a North American Benthological Society (NABS)-certified taxonomist (R. Durfee).

We used population genetic data collected from the black fly $P$. neomacropyga for comparisons of the spatial arrangement of chironomid species diversity to spatial genetic diversity in a co-occurring species.
Simuliid specimens (48-50/stream) were collected in August 2003 and were characterized according to a 307-base pair (bp) region of the mitochondrial cytochrome c oxidase subunit I (COI) gene by standard methods (Finn et al. 2006). Prosimulium neomacropyga is not confamilial with the focal community, but we regarded it as the best representative species for this analysis for 2 reasons. First, it was one of few readily identifiable species found in each of the 5 focal streams. Second, P. neomacropyga is unusual among black flies in that the females are obligately autogenous (mouthparts incapable of taking a blood meal), a quality that makes this species more similar in dispersal potential to the chironomid assemblage than to other species in its own family, which might disperse long distances in search of a blood meal (Finn and Poff 2008). Flight dispersal barriers can be 
assumed to be similar for P. neomacropyga and the Chironomidae. Therefore, we expected spatial patterns driven by dispersal limitation to be similar among these taxa.

\section{Analyses}

We tested for a positive correlation between species and genetic diversity (Vellend 2003) by comparing total (across 4 sampling y) chironomid species richness to haplotype richness at the $P$. neomacropyga mitochondrial marker. To increase sample size (and statistical power) for this spatially implicit analysis, we included 2 additional sites in the correlation analysis. Both added sites (coded GLC and SHP by Finn et al. 2006) occupy an alpine island (Longs alpine island) $\sim 20 \mathrm{~km}$ south of the focal region and were sampled using the same protocols and taxa and during the same time period as the streams in the Hagues alpine area. (These 2 Longs alpine-island sites were not included in the spatially explicit analyses because the pre-existing genetic data suggested negligible connectivity between the Hagues and Longs alpine islands.) We sampled 1 of the 7 sites (ELK) in only 3 of the $4 \mathrm{y}$ (as above). The lower sampling effort could have decreased the observed species richness at ELK compared to the other sites, so we performed the correlation and all further analyses twice (with and without the ELK site). The results did not differ in significance or interpretation between the 2 sets of analyses, so all reported results are from analyses including site ELK.

We used analysis of molecular variance (AMOVA) in the Arlequin software package (Schneider et al. 2000) as an initial test for concordance between community and population-genetic spatial patterns across the Hagues alpine island. We estimated $F_{S T}$, a measure of total partitioning of variance among vs within the 5 streams. Inputs to AMOVA were haplotype frequencies for the population level and relative species abundance (averaged across the 4 sampling y) for the community level. The overall $F_{S T}$ values measured the degree and significance of spatial structuring across the region ( $\beta$ diversity). We also used Arlequin to calculate Slatkin's linearized $F_{S T}$ (Slatkin 1995) for all pairs of sites. This statistic measured dissimilarity at the community level and genetic distance at the population level between each pair of streams. We used a Mantel test to measure the linear correlation between these 2 distance/dissimilarity matrices. A significant correlation would suggest concordant population-genetic and community structures across the region and that dispersal limitation and distance decay are drivers of commu- nity structure at this spatial scale. As a direct test of distance decay, we ran an additional Mantel test on $\log$ (Euclidean distance) vs community-level Slatkin's $F_{S T}$ for all pairs of sites.

We also were interested in the degree of change in chironomid community structure across years within streams because this measure should give some insight into the rate of ecological drift (Hubbell 2001), which in turn, can affect spatial structure at the metacommunity level. We implemented nonmetric multidimensional scaling (NMS) in the software package PC-ORD (McCune and Mefford 2006) to ordinate the streamby-year chironomid community samples, including all samples collected from 2000 to 2003 in each of the 5 streams of the Hagues alpine island and the 2 Longs alpine-island streams. Six of the 7 streams had collections from all $4 \mathrm{y}$ (ELK had only $3 \mathrm{y}$ ). Therefore, $N=27$ stream-by-year communities were included in the NMS ordination. We excluded 7 extremely rare species (those present in only 1 stream and at $<1 \%$ abundance) from the ordination to yield $N=17$ species. We $\log (x+1)$-transformed absolute abundances of these species prior to analysis and used Sørensen's dissimilarity measure to create the community distance matrix. We used multiresponse permutation procedures (MRPP; Mielke and Berry 2001) with Sørensen distances to test for differences in community structure within vs among streams. MRPP calculates a variable $A$ (chance-corrected within-stream agreement, a measure of within-stream vs among-stream homogeneity) and a $p$-value to assess significance of $A$. This MRPP essentially addressed whether year-to-year differences within streams are less variable than expected given the observed range of variability among all streams.

\section{Results}

Twenty-two species (including rare species) occurred in the Chironomidae community, and 13 mitochondrial haplotypes occurred in $P$. neomacropyga populations across the Hagues alpine-island streams. We identified 2 additional chironomid species and 3 P. neomacropyga haplotypes in the 2 Longs alpine-island streams. Local species richness varied from 9 to 18 (mean $=14.4$, median =15), and local genetic diversity varied from 3 to 7 haplotypes $($ mean $=4.7$, median $=4$ ) per stream (Table 1). Local species richness and haplotype richness were positively but marginally correlated $(r=0.55, p=$ 0.10; Fig. 2). Habitat size of these small streams (as mean wetted perimeter) varied from $135 \mathrm{~cm}$ at site ELK to $274 \mathrm{~cm}$ at site HAG (mean $=196 \mathrm{~cm}$; Table 1). Habitat size was not significantly correlated with species richness $(r=0.44, p=0.16)$ or haplotype richness $(r=0.07, p=0.44)$. 
TABLE 1. Summary information for each stream including altitude, habitat size, and total number of Chironomidae species and Prosimulium neomacropyga haplotypes identified. * indicates the 2 streams outside of Hagues alpine study region on the Longs alpine island.

\begin{tabular}{lcccc}
\hline \hline Site & $\begin{array}{c}\text { Altitude } \\
(\mathrm{m} \text { asl) }\end{array}$ & $\begin{array}{c}\text { Size (wetted } \\
\text { perimeter, cm) }\end{array}$ & $\begin{array}{c}\text { Number of } \\
\text { species }\end{array}$ & $\begin{array}{c}\text { Number of } \\
\text { haplotypes }\end{array}$ \\
\hline ELK & 3452 & 135 & 9 & 4 \\
HAG & 3447 & 274 & 16 & 6 \\
SDL & 3404 & 170 & 18 & 7 \\
NBT & 3355 & 181 & 15 & 6 \\
IPC & 3376 & 203 & 16 & 3 \\
${ }^{*}$ GLC & 3392 & 201 & 15 & 4 \\
*SHP & 3538 & 208 & 12 & 3 \\
\hline
\end{tabular}

A significant degree of spatial structuring ( $\beta$ diversity, as per AMOVA) existed at the community $\left(F_{S T}=0.16, p<0.0001\right)$ and the population-genetic $\left(F_{S T}=0.23, p<0.0001\right)$ levels across the streams in the Hagues alpine island. The spatial pattern of haplotype frequency distribution among sites followed an expected pattern of isolation by distance under neutral molecular evolution theory $(r=0.80, p=$ 0.04; Finn et al. 2006). Sites separated by the highest drainage divides also were separated by the greatest geographical distances, and haplotype frequencies were less similar at more distant streams (Fig. 1A). However, pairwise population-genetic and community distances as Slatkin's linearized $F_{S T}$ were not correlated ( $r=-0.18$, Mantel $p=0.54)$. Furthermore, no direct evidence was found for distance decay of community similarity according to a Mantel test on

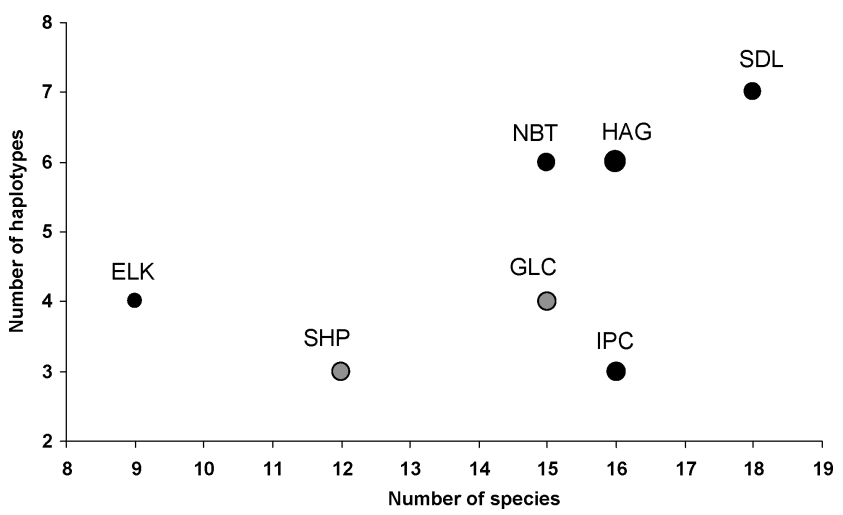

FIG. 2. Scatterplot of Prosimulium neomacropyga mitochondrial haplotype richness vs chironomid species richness at 7 alpine-stream reaches $(r=0.55, p=0.10)$. Site names are listed above their respective points. Point size is proportional to habitat size (as wetted perimeter; Table 1). The 2 headwater streams (GLC and SHP) $20 \mathrm{~km}$ south of the Hagues alpine island (Fig. 1) are shaded gray. Both axes have been truncated.

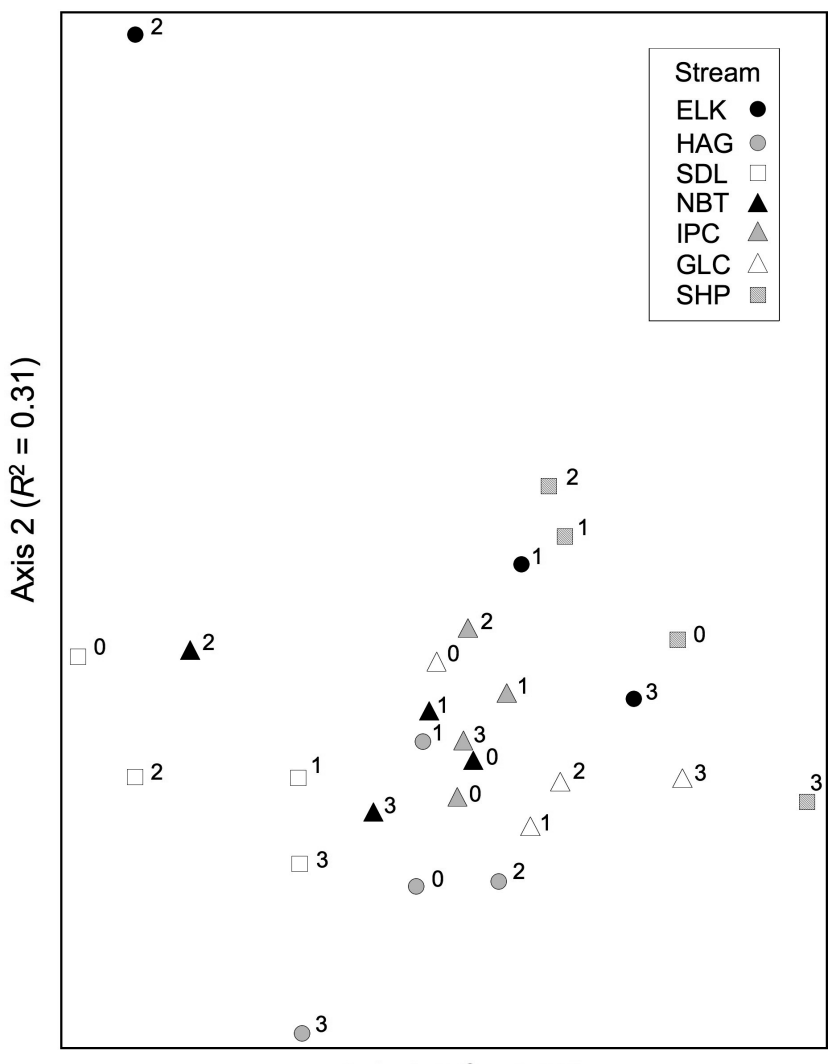

Axis $1\left(R^{2}=0.38\right)$

FIG. 3. Stream-by-year chironomid community structure for 7 alpine streams plotted in nonmetric multidimensional scaling (NMS) ordination space according to axis $1\left(R^{2}=0.38\right)$ and $2\left(R^{2}=0.31\right)$ values. A $3^{\text {rd }}$ dimension (not shown) explained an additional $24 \%$ of the total variation. Each point is coded according to stream, with replicate symbols representing different years. Small numbers to the right of each symbol represent year $(0=2000,1=2001,2=2002,3=2003)$.

community distance and geographic distance matrices $(r=-0.43$, Mantel $p=0.22$; Fig. 1B).

Ordination of the 27 total stream-by-year samples in NMS resulted in a stable, 3-dimensional solution $($ stress $=9.583$, instability $=0)$. Together, the 3 axes accounted for most of the variation in the original community distance matrix (total $R^{2}=0.93$; axis 1 $R^{2}=0.38$, axis $2 R^{2}=0.31$, axis $3 R^{2}=0.24$ ). Figure 3 shows each stream-by-year sample in ordination space according to the first 2 axes. Overall differences in community structure among sites outweighed among-year differences within sites (MRPP, $A=$ $0.42, p<0.0001)$. However, when a conservative Bonferroni adjustment $(p=0.002$ for $\alpha=0.05,21$ comparisons) or a sequential Bonferroni for multiple comparisons was applied, pairwise comparisons of $A$ were not significant for any 2 streams (Table 2). Mean within-stream (among-year) community distance (Sør- 
TABLE 2. Results of pairwise multiresponse permutation procedure (MRPP) for 7 alpine-stream chironomid communities. The variable $A$, chance-corrected within-group agreement is shown below the diagonal, and $p$-values on $A$ are shown above the diagonal. No comparisons are significant at $\alpha=0.05$ after Bonferroni adjustment. Mean within-group distance is the mean of all pairwise, within-stream Sørensen dissimilarity metrics.

\begin{tabular}{lcccccccc}
\hline \hline Site & $\begin{array}{c}\text { Mean within- } \\
\text { group distance }\end{array}$ & ELK & HAG & SDL & NBT & IPC & GLC & SHP \\
\hline ELK & 0.49 & - & 0.009 & 0.019 & 0.009 & 0.035 & 0.013 & 0.470 \\
HAG & 0.29 & 0.16 & - & 0.019 & 0.005 & 0.055 & 0.006 & 0.005 \\
SDL & 0.34 & 0.14 & 0.09 & - & 0.005 & 0.016 & 0.005 & 0.005 \\
NBT & 0.27 & 0.26 & 0.23 & 0.22 & - & 0.006 & 0.034 & 0.005 \\
IPC & 0.25 & 0.08 & 0.06 & 0.12 & 0.26 & - & 0.011 & 0.140 \\
GLC & 0.25 & 0.20 & 0.17 & 0.25 & 0.09 & 0.15 & - & 0.009 \\
SHP & 0.38 & 0.00 & 0.15 & 0.22 & 0.26 & 0.05 & 0.17 & - \\
\hline
\end{tabular}

ensen's dissimilarity) varied from 0.25 (sites IPC and GLC) to 0.49 (site ELK; Table 2). The high community turnover for site ELK also was apparent in the ordination plot (Fig. 3), in which the sample in $1 \mathrm{y}$ had an extremely high axis 2 score and low axis 1 score compared to samples in the other $2 \mathrm{y}$ for this stream.

\section{Discussion}

Comparisons of intraspecific population genetic patterns and interspecific patterns of community structure across overlapping sites can offer useful insights into the spatial mechanisms driving biological patterns. This combined approach has been applied in streams (Bonada et al. 2009, Sei et al. 2009) and elsewhere (Odat et al. 2004, Vellend 2004). Direct comparisons between these 2 levels of biological organization can be even more manageable and informative under the conceptually analogous neutral theories at the 2 levels (Kimura 1983, Hubbell 2001). We hypothesized that, because aquatic insect communities in Colorado alpine streams probably are strongly dispersal-limited (Finn and Poff 2005, 2008) and because a resident flying insect species $(P$. neomacropyga) showed marked genetic isolation by distance (Finn et al. 2006), spatial population-genetic and community structures would be positively correlated across the relatively small spatial extent of the current study.

Our results were mixed. Chironomid species richness and $P$. neomacropyga haplotype richness were positively correlated among streams. Neither richness measure was significantly correlated with habitat size, and, thus, we found neither a strong species-area nor haplotype-area relationship. This lack of pattern probably reflects the minimal variation in habitat size among our physically similar streams. A specieshabitat size relationship typically is observed across a greater range of stream sizes (Ward 1986, Finn and Poff 2005, Finn et al. 2010).
High $\beta$ diversity was confirmed at the populationgenetic and community levels by detection of significant regional-scale spatial structure. This result bolsters previous understanding from populationgenetics studies (Hughes et al. 1999, Wishart and Hughes 2003, Finn et al. 2007) and research syntheses (Lowe and Likens 2005, Meyer et al. 2007, Clarke et al. 2008) that headwater streams are exceptionally $\beta$ diverse, in accordance with their spatial isolation in the tips of stream networks. However, we found no evidence that pairwise community differences were spatially correlated with pairwise genetic distances in $P$. neomacropyga. Indeed, we found no evidence at all for distance decay of community similarity.

Two major arguments address the absence of distance decay. First, the high $\beta$ diversity among Colorado alpine streams might be more strongly influenced by differences in local environment than by the spatial structure of the landscape and stream networks. Niche-based ecological theory proposes that local habitat characteristics can selectively filter the regional species pool (Webb et al. 2010), an argument often made for streams under the implicit assumption of no dispersal limitation (Poff 1997, Statzner and Bêche 2010). By virtue of being more intimately linked to the terrestrial watershed, small headwater streams in particular are potentially more sensitive to local environmental differences than are larger streams (Lowe and Likens 2005, Meyer et al. 2007). If stronger filters exist in headwaters and filters varied among streams, greater $\beta$ diversity would result. However, distance decay would result only if differences among local environments increased consistently with distance.

We aimed to minimize variability in several important local conditions (e.g., altitude range, slope, stream size, substrate type) at the outset. We also showed previously that local environment does not explain a substantial amount of macroinvertebrate 
community variability in alpine streams of the same study region (Finn and Poff 2005). Nonetheless, potentially important unmeasured habitat variables (e.g., subtle differences in temperature regime reflecting surface flow vs groundwater inputs) could modify chironomid community patterns across these sites (Finn and Poff 2005; see also Sueker et al. 2000, Brown and Hannah 2008). Evidence for variation in local environmental conditions is seen for site ELK, where we observed some seasonal intermittency over the course of our study (the extreme value for ELK in upper left of Fig. 3 followed an exceptionally dry winter). Variance among local sites in disturbance history, in this case frequency of drying, could influence $\beta$ diversity patterns if disturbances have a strong deterministic outcome on local community structure (Vellend et al. 2007), as expected in streams (Resh et al. 1988).

Second, a potential explanation for the lack of an observed distance decay relationship in our study is a rapid rate of stochastic ecological drift, a neutral (Hubbell 2001) phenomenon. Despite the broad environmental similarity across streams, $\beta$ diversity was notably high. This pattern outweighed amongyear variation in local community structure. Furthermore, the correlation between local species richness and putatively neutral haplotype richness approached significance $(p=0.10)$, even with the relatively small sample size. These lines of evidence, combined with evidence that headwaters in general are relatively isolated in the stream network, suggest that the relative abundances of chironomid species in these alpine-stream communities might fluctuate somewhat randomly (i.e., ecological drift) in relative isolation from one another.

The concept of ecological drift, which has yet to be developed fully (Hu et al. 2006), is very similar to that of genetic drift. Ecological drift is a sampling process whereby species' relative abundances change from one generation to the next via random variation in species' birth or death rates (Hubbell 2001). Thus, different species are more or less successful at populating each generation simply by chance, and this randomness results in stochastic changes in species' relative abundance over time within sites. In many streams, particularly small headwaters, reachscale community structure can be highly variable over time (Milner et al. 2006, Mykrä et al. 2008, Mazor et al. 2009). The temporal instability in small streams might be influenced by relatively low species diversity (compared to larger streams; Finn and Poff 2005, Heino et al. 2005, Sheldon and Warren 2009). Just as expected of genetic drift, the rate of ecological drift increases significantly with decreasing sample diver- sity (Hubbell 2001). Indeed, considerable research on the diversity-stability relationship in ecology suggests that less-diverse communities are less stable temporally (Cottingham et al. 2001, Shurin et al. 2007). Therefore, headwater communities, by virtue of their low species diversity combined with their relative isolation (and decreased homogenizing influence of migration), might have a tendency to fluctuate stochastically.

Rapid, stochastic change (drift) in local community structure can decrease the ability to detect spatial pattern, such as distance decay. An analogous issue arises at the population-genetic level. When genetic drift outpaces migration in a low-dispersal region, genetic isolation by distance is not detectable (Hutchison and Templeton 1999). In the absence of the homogenizing force of migration, drift in random directions at each location erases broader spatial patterns. In our study streams, community structure did not remain constant across the 4 y of sampling (Fig. 3). Over this time period, temporal variation in community structure within streams was great enough to render insignificant all pairwise differences among streams in the ordination, in spite of highly significant overall among-stream structure. No evidence was found that community structure in each of the 7 streams in the analysis changed in the same direction in ordination space from year to year (Fig. 3). This lack of directionality of community change also suggests ecological drift.

Therefore, we have 2 distinct alternative ways, one selective and one neutral, to explain the absence of distance decay in this alpine-stream chironomid community. These explanations cannot be disentangled with the current data set, although we have presented some evidence that both might be in operation, as suggested in other stream metacommunities (Thompson and Townsend 2006, Mykrä et al. 2007, Heino and Mykrä 2008).

Interesting future research would include expanding the spatial extent and sample size of local communities and including detailed local environmental measures to test quantitatively for evidence of each of several common metacommunity models, including niche-based and neutral versions (Cottenie 2005). Because alpine-stream habitat occurs only above treeline, alpine streams are patchily distributed at nested spatial scales, including streams on alpine islands and alpine islands in mountain ranges (Finn et al. 2006). Spatial scale and pattern can have a strong influence on the ability to detect biological pattern in both population-genetic (McCulloch et al. 2009, Mullen et al. 2010) and community (Nekola and White 1999, Wiens 2002, Mykrä et al. 2007) structure. 
Furthermore, just as the spatial scale required for pattern detection varies within the population-genetic and community levels with different species and assemblage traits, it is probably unrealistic to assume that the required spatial scale for pattern detection is the same between these 2 levels of organization (but see Sei et al. 2009 for a probable exception). Increasing the maximum and decreasing the minimum (perhaps by including several sampling sites within single streams) spatial resolution of the study would provide a more comprehensive test of the varying effects of scale on population-genetic vs community pattern.

Despite the limited spatial extent of our study, we consider our novel conceptual framework to have heuristic value for the further development of metacommunity analysis in stream ecology. This framework goes beyond earlier efforts to combine community- and population-level analyses (Bonada et al. 2009, Sei et al. 2009) by emphasizing the analogous methods under neutral theory that can be applied in the same manner at both levels. Similar analytical methods will allow a more direct comparison of the influence of the unique spatial arrangement of stream networks on community and population-genetic structure of resident organisms. Our intensive temporal sampling also revealed that repeated sampling at the community level probably is essential to include in such comparative studies, particularly in systems like alpine streams that are temporally unstable. In contrast, in most cases, 1-time samples should be suitable to reveal spatial pattern at the population-genetic level. We have shown that the spatial and temporal scales of operation of potentially neutral processes can be incongruous between population-genetic and community levels, but our unified approach can provide a robust framework for assessing the mechanisms behind these differences.

\section{Acknowledgements}

We thank Ross Thompson, Russ Rader, John Wiens, and 2 anonymous referees for helpful comments on earlier versions of the manuscript, Poff laboratory group members for discussion, and Bill Black and his laboratory group for assistance with molecular analyses. Peter H. Adler identified P. neomacropyga black flies, and Rich Durfee provided Chironomidae identifications. Heidi Luter, Sudah Balakhani, and Nora Machuca helped with further laboratory work. Rocky Mountain National Park provided collecting permits. DSF was funded by a US Environmental Protection Agency Science to Achieve Results (STAR) graduate fellowship (91597401-1) and the Colorado Mountain Club Foundation.

\section{Literature Cited}

BELL, G. 2000. The distribution of abundance in neutral communities. American Naturalist 155:606-617.

Bonada, N., C. Múrria, C. Zamora-Muñoz, M. El Alami, J. M. Poquet, T. Puntí, J. L. Moreno, N. Bennas, J. AlbaTercedor, C. Ribera, and N. Prat. 2009. Using community and population approaches to understand how contemporary and historical factors have shaped species distribution in river ecosystems. Global Ecology and Biogeography 18:202-213.

BROWN, B. L., AND C. M. SwAN. 2010. Dendritic network structure constrains metacommunity properties in riverine ecosystems. Journal of Animal Ecology 79:571-580.

Brown, L. E., AND D. M. HANNAH. 2008. Spatial heterogeneity of water temperature across an alpine river basin. Hydrological Processes 22:954-967.

Chave, J., And E. G. Leigh. 2002. A spatially explicit neutral model of beta-diversity in tropical forests. Theoretical Population Biology 62:153-168.

Clarke, A., R. Mac Nally, N. Bond, and P. S. Lake. 2008. Macroinvertebrate diversity in headwater streams: a review. Freshwater Biology 53:1707-1721.

Cooper, S. D., S. J. Walde, and B. L. Peckarsky. 1990. Prey exchange rates and the impact of predators on prey populations in streams. Ecology 71:1503-1514.

CotTenie, K. 2005. Integrating environmental and spatial processes in ecological community dynamics. Ecology Letters 8:1175-1182.

Cottingham, K. L., B. L. Brown, and J. T. Lennon. 2001. Biodiversity may regulate the temporal variability of ecological systems. Ecology Letters 4:72-85.

Etienne, R. S., AND H. OlfF. 2004. A novel genealogical approach to neutral biodiversity theory. Ecology Letters 7:170-175.

FAGAN, W. F. 2002. Connectivity, fragmentation, and extinction risk in dendritic metapopulations. Ecology 83:3243-3249.

FinN, D. S., AND P. H. Adler. 2006. Population genetic structure of a rare high-elevation black fly, Metacnephia coloradensis, occupying Colorado lake outlet streams. Freshwater Biology 51:2240-2251.

FinN, D. S., M. S. Blouin, AND D. A. Lytle. 2007. Population genetic structure reveals terrestrial affinities for a headwater stream insect. Freshwater Biology 52:1881-1897.

FInN, D. S., AND N. L. Poff. 2005. Variability and convergence in benthic communities along the longitudinal gradients of four physically similar Rocky Mountain streams. Freshwater Biology 50:243-261.

Finn, D. S., And N. L. Poff. 2008. Emergence and flight activity of alpine stream insects in two years with contrasting winter snowpack. Arctic, Antarctic, and Alpine Research 40:638-646.

FinN, D. S., K. RÄsÄNEN, AND C. T. Robinson. 2010. Physical and biological changes to a lengthening stream gradient following a decade of rapid glacial recession. Global Change Biology 16:3314-3326.

Finn, D. S., D. M. Theobald, W. C. Black, and N. L. Poff. 2006. Spatial population genetic structure and limited 
dispersal in a Rocky Mountain alpine stream insect. Molecular Ecology 15:3553-3566.

Gomi, T., R. C. Sidle, and J. S. Richardson. 2002. Understanding processes and downstream linkages of headwater systems. BioScience 52:905-916.

Gordon, N. D., T. A. McMahon, and B. L. Finlayson. 1992. Stream hydrology: an introduction for ecologists. John Wiley and Sons, New York.

Grant, E. H. C., W. H. LOWE, AND W. F. FAGAN. 2007. Living in the branches: population dynamics and ecological processes in dendritic networks. Ecology Letters 10:165-175.

Grossman, G. D., P. B. Moyle, and J. O. Whitaker. 1982. Stochasticity in structural and functional characteristics of an Indiana stream fish assemblage: a test of community theory. American Naturalist 120:423-454.

HeINo, J. 2005. Metacommunity patterns of highly diverse stream midges: gradients, chequerboards, and nestedness, or is there only randomness? Ecological Entomology 30:590-599.

HeINo, J., AND H. MYKRÄ. 2008. Control of stream insect assemblages: roles of spatial configuration and local environmental factors. Ecological Entomology 33:614622.

Heino, J., J. Parviainen, R. Paavola, M. Jehle, P. Louhi, and T. MuOTKA. 2005. Characterizing macroinvertebrate assemblage structure in relation to stream size and tributary position. Hydrobiologia 539:121-130.

Hu, X.-S., F. He, and S. P. Hubbell. 2006. Neutral theory in macroecology and population genetics. Oikos 113: 548-556.

Hubbell, S. P. 2001. The unified neutral theory of biodiversity and biogeography. Princeton University Press, Princeton, New Jersey.

Hughes, J. M. 2007. Constraints on recovery: using molecular methods to study connectivity of aquatic biota in rivers and streams. Freshwater Biology 52:616-631.

Hughes, J. M., P. B. Mather, A. L. Sheldon, and F. W. Allendorf. 1999. Genetic structure of the stonefly, Yoraperla brevis, populations: the extent of gene flow among adjacent montane streams. Freshwater Biology 41:63-72.

Hughes, J. M., D. J. Schmidt, And D. S. Finn. 2009. Genes in streams: using DNA to understand the movement of freshwater fauna and their riverine habitat. BioScience 59:573-583.

Hutchison, D. W., And A. R. Templeton. 1999. Correlation of pairwise genetic and geographic distance measures: inferring the relative influences of gene flow and drift on the distribution of genetic variability. Evolution 53: 1898-1914.

KimurA, M. 1968. Evolutionary rate at the molecular level. Nature 217:624-626.

KimURA, M. 1983. The neutral theory of molecular evolution. Cambridge University Press, Cambridge, UK.

Lowe, W. H., AND G. E. LiKens. 2005. Moving headwater streams to the head of the class. BioScience 55:196-197.

LyTLE, D. A. 2008. Life-history and behavioural adaptations to flow regime in aquatic insects. Pages 122-138 in J. Lancaster and R. A. Briers (editors). Aquatic insects: challenges to populations. CABI International, London, UK.

MacArthur, R. H., and E. O. Wilson. 1967. The theory of island biogeography. Princeton University Press, Princeton, New Jersey.

Mazor, R. D., A. H. Purcell, and V. H. Resh. 2009. Longterm variability in bioassessments: a twenty-year study from two northern California streams. Environmental Management 43:1269-1286.

McCulloch, G. A., G. P. Wallis, and J. M. Waters. 2009. Do insects lose flight before they lose their wings? Population genetic structure in subalpine stoneflies. Molecular Ecology 18:4073-4087.

McCune, B., AND M. J. MefFord. 2006. PC-ORD. Multivariate analysis of ecological data. Version 5. MjM Software Design, Gleneden Beach, Oregon.

Merritt, R. W., and K. W. Cummins (editors). 1996. Aquatic insects of North America. $3^{\text {rd }}$ edition. Kendall/Hunt, Dubuque, Iowa.

Meyer, J. L., D. L. Strayer, J. B. Wallace, S. L. Eggert, G. S. Helfman, and N. E. LeOnard. 2007. The contribution of headwater streams to biodiversity in river networks. Journal of the American Water Resources Association 43:86-103.

MielKe, P. W. J., AND K. J. BerRy. 2001. Permutation methods: a distance function approach. Springer, Berlin, Germany.

Milner, A. M., S. C. Conn, And L. E. Brown. 2006. Persistence and stability of macroinvertebrate communities in streams of Denali National Park, Alaska: implications for biological monitoring. Freshwater Biology 51: 373-387.

Monaghan, M. T., C. T. Robinson, P. SpaAK, And J. V. Ward. 2005. Macroinvertebrate diversity in fragmented Alpine streams: implications for freshwater conservation. Aquatic Sciences 67:454-464.

Moritz, C. 2002. Strategies to protect biological diversity and the evolutionary processes that sustain it. Systematic Biology 51:238-254.

Mullen, L. B., H. A. Woods, M. K. Schwartz, A. J. Sepulveda, AND W. H. LowE. 2010. Scale-dependent genetic structure of the Idaho giant salamander (Dicamptodon aterrimus) in stream networks. Molecular Ecology 19: 898-909.

MүкrÄ, H., J. Heino, And T. MuotKa. 2007. Scale-related patterns in the spatial and environmental components of stream macroinvertebrate assemblage variation. Global Ecology and Biogeography 16:149-159.

MүкRÄ, H., J. Heino, AND T. MuOtKA. 2008. Concordance of stream macroinvertebrate assemblage classifications: how general are patterns from single-year surveys? Biological Conservation 141:1218-1223.

NeKola, J. C., And P. S. White. 1999. The distance decay of similarity in biogeography and ecology. Journal of Biogeography 26:867-878.

Odat, N., G. JetschKe, and F. H. Hellwig. 2004. Genetic diversity of Ranunculus acris L. (Ranunculaceae) populations in relation to species diversity and habitat type in grassland communities. Molecular Ecology 13:1251-1257. 
Palmer, M. A., J. D. Allan, and C. A. Butman. 1996. Dispersal as a regional process affecting the local dynamics of marine and stream benthic invertebrates. Trends in Ecology and Evolution 11:322-326.

Palmer, M. A., C. M. Swan, K. Nelson, P. Silver, and R. Alvestad. 2000. Streambed landscapes: evidence that stream invertebrates respond to the type and spatial arrangement of patches. Landscape Ecology 15:563-576.

Poff, N. L. 1997. Landscape filters and species traits: towards mechanistic understanding and prediction in stream ecology. Journal of the North American Benthological Society 16:391-409.

Pringle, C. M., R. J. Naiman, G. Bretschko, J. R. Karr, M. W. Oswood, J. R. Webster, R. L. Welcomme, AND M. J. Winterbourn. 1988. Patch dynamics in lotic systems: the stream as a mosaic. Journal of the North American Benthological Society 7:503-524.

Resh, V. H., A. V. Brown, A. P. Covich, M. E. Gurtz, H. W. Li, G. W. Minshall, S. R. Reice, A. L. Sheldon, J. B. Wallace, AND R. C. Wissmar. 1988. The role of disturbance in stream ecology. Journal of the North American Benthological Society 7:433-455.

SchneIder, S., D. Roessli, AND L. Excoffier. 2000. Arlequin version 2.000: a software for population genetics data analysis. Genetics and Biometry Laboratory, University of Geneva, Switzerland.

Sei, M., B. K. Lang, And D. J. Berg. 2009. Genetic and community similarities are correlated in endemic-rich springs of the northern Chihuahuan Desert. Global Ecology and Biogeography 18:192-201.

SheldON, A. L., AND M. L. WARREN. 2009. Filters and templates: stonefly (Plecoptera) richness in Ouachita Mountains streams, USA. Freshwater Biology 54:943-956.

Shurin, J. B., S. E. Arnott, H. Hillebrand, A. Longmuir, B. Pinel-Alloul, M. Winder, And N. D. Yan. 2007. Diversity-stability relationship varies with latitude in zooplankton. Ecology Letters 10:127-134.

SlatKIN, M. 1995. A measure of population subdivision based on microsatellite allele frequencies. Genetics 139: 457-462.

StATZNER, B., AND L. A. BÊCHE. 2010. Can biological invertebrate traits resolve effects of multiple stressors on running water ecosystems? Freshwater Biology 55:80-119.

Sueker, J. K., J. N. Ryan, C. Kendall, and R. D. Jarkett. 2000. Determination of hydrologic pathways during snowmelt for alpine/subalpine basins, Rocky Mountain National Park, Colorado. Water Resources Research 36:63-75.
Thompson, R., And C. Townsend. 2006. A truce with neutral theory: local deterministic factors, species traits and dispersal limitation together determine patterns of diversity in stream invertebrates. Journal of Animal Ecology 75:476-484.

Thorp, J. H., M. C. Thoms, and M. D. Delong. 2006. The riverine ecosystem synthesis: biocomplexity in river networks across space and time. River Research and Applications 22:123-147.

TownSEND, C. R. 1989. The patch dynamics concept of stream community ecology. Journal of the North American Benthological Society 8:36-50.

Urban, M. C., D. K. Skelly, D. Burchsted, W. Price, and S. LOWRY. 2006. Stream communities across a rural-urban landscape gradient. Diversity and Distributions 12: 337-350.

VELLEND, M. 2003. Island biogeography of genes and species. American Naturalist 162:358-365.

Vellend, M. 2004. Parallel effects of land-use history on species diversity and genetic diversity of forest herbs. Ecology 85:3043-3055.

Vellend, M., K. Verheyen, K. M. Flinn, H. Jacquemyn, A. Kolb, H. Van Calster, G. Peterken, B. J. Graae, J. Bellemare, O. Honnay, J. Brunet, M. Wulf, F. Gerhardt, and M. Hermy. 2007. Homogenization of forest plant communities and weakening of species-environment relationships via agricultural land use. Journal of Ecology 95:565-573.

WARD, J. V. 1986. Altitudinal zonation in a Rocky Mountain stream. Archiv für Hydrobiologie, Supplement 74: 133-199.

WARD, J. V. 1994. Ecology of alpine streams. Freshwater Biology 32:277-294.

Webb, C. T., J. A. Hoeting, G. M. Ames, M. I. Pyne, and N. L. PofF. 2010. A structured and dynamic framework to advance traits-based theory and prediction in ecology. Ecology Letters 13:267-283.

Wiens, J. A. 2002. Riverine landscapes: taking landscape ecology into the water. Freshwater Biology 47:501-515.

Wishart, M. J., AND J. M. Hughes. 2003. Genetic population structure of the net-winged midge, Elporia barnardi (Diptera: Blephariceridae) in streams of the southwestern Cape, South Africa: implications for dispersal. Freshwater Biology 48:28-38.

WrIGHT, S. 1943. Isolation by distance. Genetics 28:114-138.

Received: 10 March 2010

Accepted: 26 August 2010 